\title{
The 1st John Wales Memorial Lecture 2018: Delivering better diabetes care - it's about time!
}

\author{
PETER H WINOCOUR
}

In recognition of our founding chairman Dr John Wales, the Association of British Clinical Diabetologists (ABCD) established an annual lecture in his name. I was privileged to deliver the inaugural lecture in May 2018 in Glasgow. In honouring John, I wanted to ensure that the content of the lecture was themed to be challenging and reflected the influence that John had, inspiring me to talk the truth as one sees it. I chose the broad concept of time - past, present and future. In summary, I stated that many of the challenges recognised over 20 years ago remain, and I believe that, as a national body of experts, ABCD can take the lead in rectifying this.

Br J Diabetes 2018;18:175-178

Key words: diabetes, glycaemic targets, organisation of care, leadership, challenging dogma

\section{Dr John Wales - 'his life and times'}

John Kenneth Wales was born on 16 October 1937 and died following a sudden illness in Helsinki on 10 August 2017. Although most of his adult life was spent in Yorkshire, he spent his childhood on the other side of the Pennines where he was educated at Burnley Grammar School. He studied medicine at the University of Leeds where he spent most of his professional career, although he also spent time training and working in the Hammersmith Hospital, London and in New York and Washington. After his retirement in 2002 he took on a role as visiting diabetologist and lecturer at the Beijing Chaoyong Diabetes Hospital in China. He had a love of music and developed skills as a composer of classical music.

John was instrumental in establishing ABCD in 1997 alongside Professor Ken Shaw and Dr Richard Greenwood, recognising it was 'time for a change'. More than 20 years on, one of John's many legacies is that $A B C D$ is firmly established as the professional body for specialist diabetologist physicians in the UK.

ENHIDE (East and North Herts Institute of Diabetes and Endocrinology), Howlands Clinic, QEll Hospital, Welwyn Garden City, Herts AL7 4HQ, UK

Address for correspondence: Dr Peter $\mathrm{H}$ Winocour ENHIDE (East and North Herts Institute of Diabetes and Endocrinology), Howlands Clinic, QEll Hospital, Welwyn Garden City, Herts AL7 4HQ, UK E-mail: peter.winocour@nhs.net

https://doi.org/10.15277/bjd.2018.197

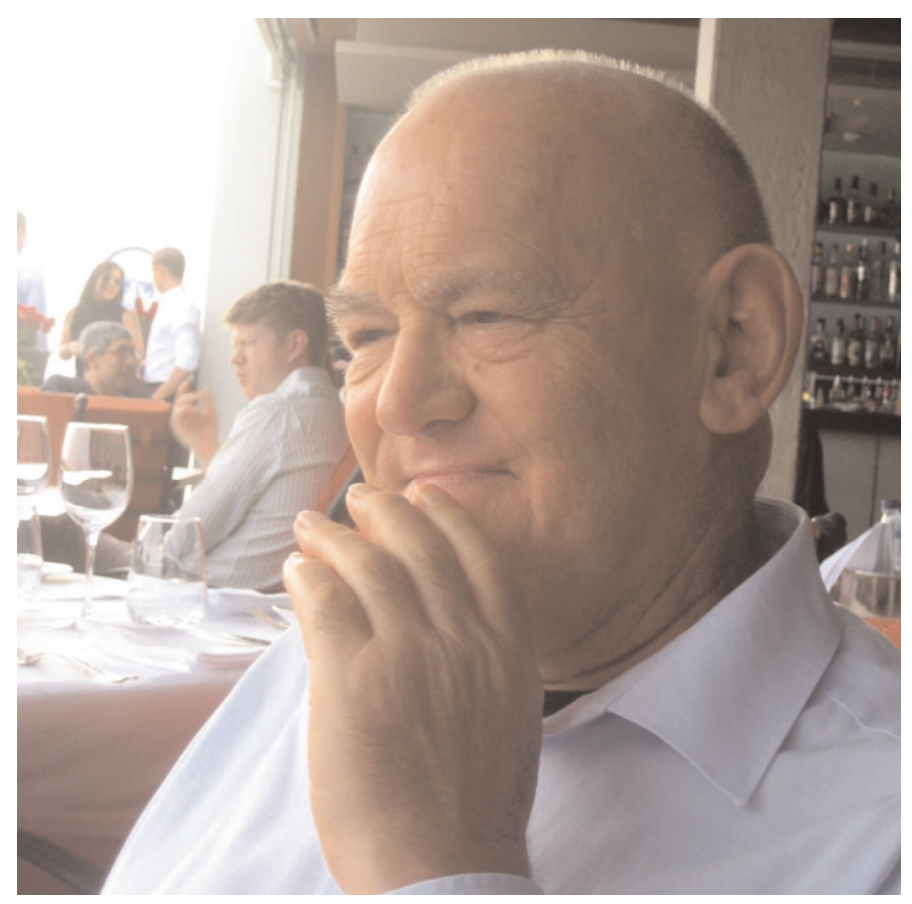

Dr John Wales, first Chairman of $A B C D$

The National Service Framework for Diabetes 2002 and 'future times'

This was produced by the Department of Health in 2002. There were 12 standards with an expectation these would be delivered by 2013. There was no ring-fenced funding to enable realisation of the delivery strategy. The document was ambitious yet vague, with more focus on process and structures rather than outcomes. For example, Standard 12 stated that all people with diabetes requiring multi-agency support WILL receive integrated health and social care. This, of course, remains an important but unresolved aspect of wider health care, along with many of the other standards yet to be attained.

'Time to take stock and the passage of time' Encouraged by John Wales, Ken Shaw, Richard Greenwood and I undertook a national survey of secondary care diabetes services throughout the UK in 2000, under the auspices of $A B C D .{ }^{1-4}$ This demonstrated major regional and national variation in provision 


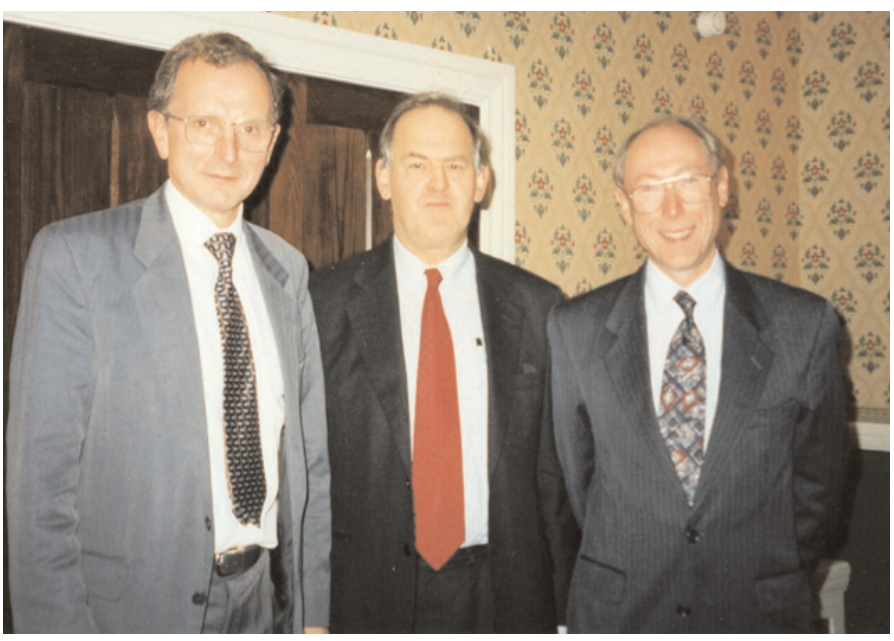

The 'gang of three' - founders of ABCD: Dr Richard Greenwood, Dr John Wales, Professor Ken Shaw

and a sizeable number of single-handed consultant-led diabetes services. In 2017 the ABCD Workforce Survey (in collaboration with Diabetes UK, Society for Endocrinology and the Royal Colleges of Physicians) demonstrated that the whole time equivalent consultant numbers per 100,000 population had risen over the intervening period from 0.67 to 1.43 , although the significant (and often longstanding) geographical variation in resourcing of services persisted with a residual almost twofold variation in consultant numbers throughout the UK. ${ }^{5}$

\section{'Time after time'}

After an EASD meeting in Budapest in 2002 where I recollect discussions with John, I was fortunate to have a paper published in the British Medical Journal challenging the targets for diabetes care as being often impractical and attainable in only $50-70 \%$ of individuals in research studies, requiring polypharmacy which people with diabetes would not comply with long term. ${ }^{6}$ Subsequent to this, the National Diabetes Audit reported either modest or no change in target attainment of $\mathrm{HbA}_{1 \mathrm{c}}(\leq 58 \mathrm{mmol} / \mathrm{mol})$, blood pressure $(\leq 140 / 80 \mathrm{mmHg})$ and cholesterol $(<5 \mathrm{mmol} / \mathrm{l})$ over the period from 2012 to 2017 , with $65-67 \% \mathrm{HbA}_{1 \mathrm{c}}$ attainment over that time and $41 \%$ attainment of all three treatment targets in 2017. Vindication without satisfaction!

\section{'Time costs money'}

The economics of diabetes are stark. The costs of diabetes (direct and indirect) had been estimated at $\mathrm{f} 10$ billion, at a time when this reflected $10 \%$ of the total NHS budget when prevalence of the condition was stated to be no more than $6 \%$. Whilst specialist services quite rightly focus on ensuring effective specialist care of type 1 diabetes and those with complex and complicated type 2 diabetes, the bulk (90\%) of those diagnosed have type 2 diabetes wherein most of the cost of medications and complications lie. The projected almost doubling of NHS expenditure for diabetes by 2035 makes it clear to me that current care models and approaches to the whole population with diabetes need to change. The current focus on diabetes prevention, whilst laudable, is perhaps more honestly stated as a diabetes delay project. There is a need to 'wake up and smell the coffee' - most diabetes care $(80 \%)$ takes place in primary care, often delivered by practice nurses, and it is from this setting that the majority of care costs are ultimately derived. The considerable pressure to deliver a comprehensive range of services in primary care, the lack of defined succession planning for senior GPs and practice nurses with an interest in diabetes management and the sheer numbers with diabetes $(6-12 \%)$ suggest to me that the current focus on eight care processes (stated over 15 years ago as a requirement but still not met) and QoF targets can be managed differently with much more effective use of clinical information to highlight the large numbers at greatest need and ensure an end to therapeutic inertia.

\section{'Time for leadership'}

Integrated models of diabetes care were promoted by NHS Diabetes and $A B C D$ over 10 years ago. Despite the exhortation for 'Teams without Walls', 7 there are perverse incentives, layers of bureaucracy and organisational boundaries that often impede these approaches. Diabetologists are usually employed as physicians by acute trusts, and taking a wider role serving whole communities and healthcare systems alongside primary and hospital care is certainly not the norm. $A B C D$ have rightfully recognised from the feedback from trainees and younger consultants that we need to better resource the future leaders of diabetes care. The ABCD Mentorship and Leadership programmes are designed to rectify this. As a professional body we need to step up to the plate and take a leading role in wider service delivery.

\section{'Time to reappraise and challenge dogma'}

This is an issue I feel John Wales would have been particularly supportive of - the following quote from John Maynard Keynes exemplifies this: "The difficulty lies not so much in developing new ideas as in escaping from old ones". We can apply this notion to the continued mantra heard that pioglitazone is linked to bladder cancer despite the largest data set refuting this. ${ }^{8}$ Other examples of changes in evidence that have faced resistance over recent years are the perceived cardiovascular dangers of sulfonylureas, the over-assiduous targets of $\mathrm{HbA}_{1 \mathrm{c}}$ in older patients with chronic kidney disease (CKD), and reluctance to initiate statins in those with diabetes and fatty liver disease.

\section{Time - 'the 4th dimension'}

Do we pay sufficient (or indeed any) attention to the notion of time in our care planning?

Early onset retinopathy and type 2 diabetes onset in people aged less than 40 need a more active focus. The timeline of many of the issues we seek to minimise have a slow indolent process with often a sudden precipitate event that in retrospect could have been seen coming - vitreous haemorrhage, acute thrombotic events and acute foot attacks in high-risk cases all come to mind. Due diligence to identify such risks with fast track input is perhaps rather too sophisticated in the way current 
health care is provided, but better use of big data with patient consent might enable some damage limitation. By contrast, the rapid development of acute hypoglycaemia in hypo unaware cases can have catastrophic consequences whilst driving, although we would hope sensors with alarms may pre-empt such events in the future.

\section{'The best of times, the worst of times'}

This quote from Charles Dickens in A Tale of Two Cities feels apposite to the current health environment we work in. On the one hand we have exciting new therapeutic avenues opening up with potential direct cardio-renal benefits from gliflozins and GLP1 analogues. In contrast, headlines every winter as to our 'Third World NHS which is dying' and our own direct observations that the winter crisis is a year-round affair suggests that our current health care model is indeed broken.

\section{'The times they are a changing ...'}

Bob Dylan may have had socio-political events in mind when this song was written in 1964. However, in 2018 we are seeing this now in many respects, but particularly the progressive dramatic change in population demographics, with at least $10 \%$ of those aged over 75 currently living with diabetes, and with a greater than $60 \%$ increase in the population aged over 65 projected by 2032. The consequent multi-morbidity aligned with complexity of therapy selection makes individualised care more challenging.

\section{'Just in time?' ... 'One step at a time'}

Credit is undoubtedly due to our National Clinical Leads who secured funding to improve inpatient, foot care and structured education whilst rolling out a clinician-led process to minimise unwarranted variation in patient outcomes and to finally promote the need for separate resourcing of specialist type 1 diabetes adult care as part of the work of the ABCD collaborative. However, in reality the 'wheels grind exceedingly slow'!

I started as a single-handed consultant general physician with an interest in diabetes and endocrinology with support from two diabetes specialist nurses in 1993. Our department (possibly now over-grandly titled ENHIDE - The East and North Herts Institute of Diabetes and Endocrinology) has grown to a team with over 50 multi-disciplinary personnel delivering 7-day inpatient care, an integrated foot team, a MODY service, coordinated joint diabetes and ophthalmological care of patients with severe active retinopathy, diabetes renal and pump clinics, close collaboration with primary and community diabetes nursing care and a closely integrated children and young adults diabetes service. This took 25 years to build - playing the long game seems key.

\section{'Good times ahead' - 'better use of time'}

We should take an optimistic view but will need to work tirelessly to change the health systems. We can use our expertise and fully exploit IT as part of a whole system care model to enable focused population health surveillance which would complement individual tailored ambulatory and acute inpatient care.

Like many innovative services, ENHIDE has developed tele-

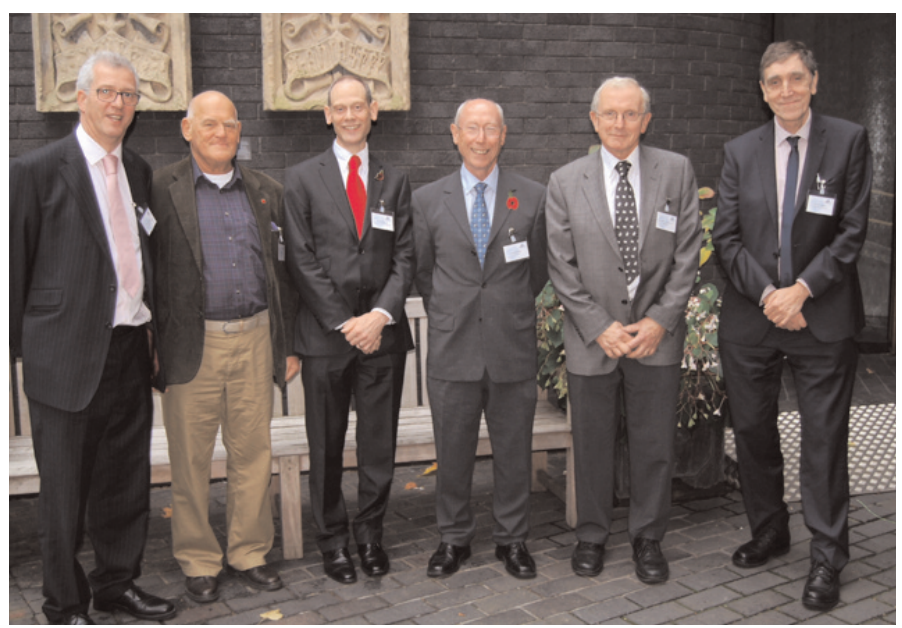

The first six chairs of $A B C D-R C P L$ 2014: Drs Peter Winocour, John Wales, Rob Gregory, Ken Shaw, Richard Greenwood and Chris Walton

health and other approaches to support vulnerable groups of patients, recognising that current structures for care - notably standard outpatient clinics - do not work very well and are VERY expensive. Managing disengaged young adults with type 1 diabetes (we identified 148 in ENHIDE) using flexible support with young adult care workers and dedicated DSN time underpinned by access to all available new technology, appropriate psychosocial support and consultant overview is proving more fruitful than futile efforts to support this 'lost tribe' with a traditional clinic model that does not work for them.

By contrast, the number of patients with diabetes and CKD is large and growing (currently over 25\% on GP diabetes registers, $80 \%$ of whom are solely under primary care). Clinics again are not the answer and national and international surveys have revealed major deficiencies in care processes and appropriate target attainment through clinic-based models. ${ }^{9}$ Our diabetes renal telehealth pilot has delivered virtual clinical review of large numbers through effective information delivery. This has enabled the extent of unmet clinical need to be identified, supported by telehealth conversations with primary care to enable holistic case management as well as upskilling the primary care team.

\section{'Managing complex diabetes takes time'}

By way of example, in the lecture I focused on the challenge of managing people with diabetes and CKD and defined 15 often inter-related pillars of care all deserving of assessment and management. ${ }^{9}$ Currently, outpatient clinics have been more and more managerially driven to be more productive (ie, to see more patients). Realistically comprehensive evaluation is not possible in a 20 minute clinic appointment. We should evaluate changes in renal measures of filtration and excretory function, glycaemic control and enhanced hypoglycaemic risk, and anaemia - its cause, its management and its impact on interpretation of $\mathrm{HbA} \mathrm{Ac}_{1 \mathrm{c}}$. There is also a need for recognition of the vulnerability of hospitalisation with increased risks of acute kidney injury, vascular and infective issues, feet, metabolic bone and retinal 
complications and attention to frequent co-morbid obesity and smoking. ${ }^{9}$ Commissioners and service planners may want to take on board the exhortation 'festina lente'.

\section{'Time for some home truths'}

I previously mentioned the realistic prospects of target attainment and now pose questions perhaps we need to ask ourselves.

- Just how efficacious are the range of therapies we have?

- If we optimise weight control and metabolic and vascular risk factors with current and future therapies, will that mean that we would be able to avoid or delay complications in the majority of cases?

- Is remission of diabetes a niche area or attainable for large numbers of people?

- When we provide specialist complication clinics, are we in the business of damage limitation or are adverse outcomes already on a fixed trajectory in many cases?

- If we manage metabolic and CVD risk in patients who remain obese, do we need to accept there will be less efficacy?

\section{'Happy endings?'}

John Wales was a great character and an inspiration to many. I mentioned that John latterly spent time working in China - one Chinese proverb I found may offer us an approach to deliver better diabetes care than at present: "The spectators see more of the game than the players".

Perhaps it is now 'time' for diabetologists to take a step back and look at the bigger picture?

\section{Conflict of interest None \\ Funding None}

\section{References}

1. Winocour PH, Ainsworth A, Wiliams R. Association of British Clinical Diabetologists $(A B C D)$ survey of secondary care services for diabetes in the United Kingdom, 2000. 1: Methods and major findings. Diabet Med 2002;19:327-3.

2. Winocour PH, Ainsworth A, Ford M. Association of British Clinical Diabetologists (ABCD) survey of specialist diabetes care services in the UK, 2000. 2 Workforce issues, roles and responsibilities of diabetes specialist nurses. Diabet Med 2002;19(Suppl 4):27-31.

3. Winocour PH, Morgan J, Ainsworth A. Association of British Clinical Diabetologists $(A B C D)$ survey of specialised diabetes care services in the UK, 2000. 3: Podiatry services and related foot care issues. Diabet Med 2002;19(Suppl 4):32-8.

4. Winocour PH, Gosden C, Walton C, et al. Association of British Clinical Diabetologists (ABCD) and Diabetes-UK survey of specialist diabetes services in the UK, 2006. 1: The consultant physician perspective. Diabet Med 2008;25:643-50. https://doi.org/10.1111/j.1464-5491.2008.02449.x

5. George S. Workforce survey 2016-2017. https://abcd.care/sites/abcd.care/ files/resources/SPG\%20George\%20to\%20publish.pdf

6. Winocour PH. Effective diabetes care - a need for realistic targets. BMJ 2002;324:1577-80.

7. NHS Diabetes. Commissioning diabetes without walls. 2009. https:// www.yearofcare.co.uk/sites/defaultffiles/images/diabeteswithoutwalls1.pdf

8. Gallagher A, Winocour PH, on behalf of the Association of British Clinical Diabetologists. Pioglitazone use and risk of bladder cancer: population based cohort study (letter). BMJ 2016;352:11541.

https://doi.org/10.1136/bmj.i1541

9. Winocour PH. Diabetes and chronic kidney disease: an increasingly common multi-morbid disease in need of a paradigm shift in care. Diabet Med 2018;35:300-5. https://doi.org/10.1111/dme.13564 